\title{
Comparação de métodos de extração da solução do solo
}

\author{
$\overline{\text { Edivan R. de Souza' }{ }^{1} \text {, Hidelblandi F. de Melo }{ }^{2} \text {, Brivaldo G. de Almeida }{ }^{2} \text { \& Diego V. M. de Melo }}{ }^{2}$
}

RESUMO

A composição iônica da solução do solo é de grande relevância para o monitoramento da disponibilidade de nutrientes e manejo da adubação tal como, também, processos de contaminação ambiental. Assim, métodos mais viáveis que estimem a composição iônica desta solução, são bem aceitos na literatura. Esta pesquisa objetiva avaliar o desempenho de métodos de extração da solução do solo como: via pasta de saturação, extratores munidos de cápsulas porosas e relações solo:água de 1:2; 1:5 e 1:10, com e sem processo de filtragem. Utilizaram-se amostras de Neossolo Flúvico em colunas de PVC e soluções saturantes correspondentes a $0 ; 20 ; 30 ; 40 ; 50 ; 60 ; 70 ; 80 ; 90 ; 100 ; 110$ e $120 \mathrm{mmol}_{\mathrm{c}} \mathrm{L}^{-1} \mathrm{de} \mathrm{NaCl}$, em delineamento em blocos ao acaso com quatro repetições. Os extratores munidos de cápsulas porosas apresentam-se como alternativa viável para extração da solução do solo e monitoramento da condutividade elétrica, do potencial osmótico e composição iônica. Os extratos aquosos em diferentes relações solo:água apresentam potencial de uso para extração e posterior caracterização da fase aquosa do solo. O processo de filtragem pode ser descartado quando o intuito é a determinação somente da condutividade elétrica.

Palavras-chave: potencial osmótico, cápsulas extratoras porosas, relações solo:água

\section{Comparison of methods for extracting soil solution}

\begin{abstract}
The ionic composition of the soil solution is of great importance for monitoring the availability of nutrients and fertilizer management, as well as processes of environmental contamination. Thus, the most viable methods to estimate the composition of the soil solution are well accepted in the literature. This study aims to evaluate the performance of the extraction methods by saturation paste, porous extractor cups and soil:water relations of 1:2, 1:5 and 1:10, with and without filtering process. Samples of Fluvic Neossol were used in PVC columns and saturated with solutions corresponding to 0, 20, 30, 40, 50, 60, 70, 80, $90,100,110$ and $120 \mathrm{mmol}_{\mathrm{C}} \mathrm{L}^{-1} \mathrm{NaCl}$, in randomized block design with four replications. The extractors with porous cup are indicated to extract the soil solution for monitoring the electrical conductivity, osmotic potential and ionic composition. The aqueous extract in different soil:water ratio has a potential use for the extraction and subsequent characterization of the aqueous phase of soil. The filtering process can be discarded when the intention is only to determine the electrical conductivity.
\end{abstract}

Key words: osmotic potential, extracting porous cups, soil:water relations 


\section{INTRODUÇÃO}

A caracterização das fases sólida (mineral e orgânica) gasosa e líquida do solo é de grande relevância para que se possa inferir sobre os atributos físicos, químicos e biológicos do solo e, consequentemente, na adoção de práticas de manejo adotadas. Enquanto a fase sólida apresenta uma resistência maior à mudança em sua composição primária (areia, silte e argila), as fases gasosa e líquida, além de estarem intimamente relacionadas, apresentam-se bastante variáveis dependendo do manejo utilizado.

O conhecimento da composição da fase líquida, comumente denominada solução do solo, é de fundamental importância para o monitoramento da disponibilidade de nutrientes para as plantas, processos de contaminação ambiental e aqueles relacionados ao entendimento da dinâmica da caracterização e avaliação de solos afetados por sais.

Dentre as técnicas desenvolvidas para extração da solução do solo encontrados na literatura, destacam-se os métodos do deslocamento (Elkhatib et al., 1986), centrifugação (Adams et al., 1980; Miranda et al., 2006), pasta de saturação do solo (Richards, 1954; Souza et al., 2012); cápsulas extratoras porosas (Lao et al., 2004; Lima, 2009) e extratos aquosos em diferentes relações solo:água (Richards, 1954; Chowdhury et al., 2011a,b). O método da pasta saturada é um método destrutivo, o que acarreta mudanças na estrutura do solo e, em consequência, em sua porosidade, além de ser subjetivo com relação ao ponto indicador de saturação do solo e de lenta extração; entretanto, ainda é um dos métodos tidos como referência no Brasil, sobretudo quanto aos estudos de solos propensos à contaminação ambiental e bastante usado na calibração dos demais métodos.

Um método que vem ganhando destaque é o de extração da solução do solo por meio de cápsulas porosas (Lao et al., 2003; Dias et al., 2005; 2006; Blanco et al., 2008; Lima, 2009; Silva Júnior et al., 2010; Oliveira et al., 2011; Marques et al., 2012) uma vez que representa as condições reais de umidade e concentrações dos elementos disponíveis às plantas, além de possibilitar a coleta da fase líquida diretamente em campo e não ser destrutivo, propiciando a repetição de coleta da solução do solo no mesmo local, favorecendo monitoramentos por longos períodos.

Os métodos que usam extratos aquosos em diferentes relações solo:água, têm gerado discussões estimulando investigações científicas a respeito da proporção solo:água, uma vez que são adotadas quantidades diferenciadas de água, causando mudanças na diluição dos íons presentes na solução. Além disto, discute-se a necessidade ou não do processo de filtragem das amostras após a extração. Neste contexto é importante frisar a carência de estudos comparativos entre métodos de extração da solução do solo (Schlotter et al., 2012).

Gloaguen et al. (2009a) enfatizam, ao propor um método simples de extração sequencial utilizando um sistema de vácuo, que diante das diversas técnicas de amostragem a diferença de volume e de composição da solução tem sido fonte constante de discussões; esses autores discorrem, ainda, que os tipos de solo e de manejo exercem grande influência na porosidade do solo e, consequentemente, na disponibilidade da solução no solo; neste sentido é necessário que seja avaliado o desempenho de diferentes métodos em classes de solos distintas tentando entender a dinâmica da composição da solução do solo.

Assim, o presente estudo objetivou comparar três métodos de extração da solução do solo: método padrão da pasta saturada, cápsulas extratoras porosas e extrato aquoso solo:água, nas relações 1:2; 1:5 e 1:10, com e sem processo de filtragem em amostras de solo da Classe Neossolo Flúvico utilizando colunas de PVC e soluções de saturação de $0 ; 20 ; 30 ; 40 ; 50 ; 60 ; 70$; $80 ; 90 ; 100 ; 110$ e $120 \mathrm{mmol}_{\mathrm{c}} \mathrm{L}^{-1}$. As variáveis utilizadas para avaliar as diferenças entre os métodos foram condutividade elétrica, potencial osmótico, sódio e cloreto solúveis.

\section{Material e Métodos}

O experimento foi conduzido no Laboratório de Física do Solo da Universidade Federal Rural de Pernambuco, Recife, PE, entre os meses de setembro a dezembro de 2011.

O solo utilizado para análise foi classificado como Neossolo Flúvico coletado na profundidade de $0-30 \mathrm{~cm}$ na fazenda experimental "Nossa Senhora do Rosário", Município de Pesqueira, PE; nesta área vêm sendo conduzidos experimentos que abordam a produtividade de culturas susceptíveis e tolerantes à salinidade, bem como de dinâmica da água e sais em solos predominantemente de origem sedimentar, como é o caso dos Neossolos Flúvicos.

$\mathrm{O}$ experimento foi desenvolvido em blocos inteiramente casualisados com quatro repetições e doze tratamentos representados pelas soluções de saturação. $\mathrm{O}$ experimento foi subdividido em três etapas (obtenção da solução pelos métodos de extração via cápsula extratora porosa, via pasta de saturação e relações solo-água). Os dados foram avaliados com o uso de parâmetros de estatística descritiva (média e desvio padrão) e ajuste de equações de regressão.

Para caracterização do solo foram utilizadas amostras de terra fina secadas ao ar (TFSA) e passadas em malha de $2 \mathrm{~mm}$ (Tabela 1).

Tabela 1. Caracterização física e química do solo coletado de $0-30 \mathrm{~cm}$ de profundidade

\begin{tabular}{lc}
\hline \multicolumn{1}{c}{ Atributos do solo* } & Valor \\
Areia total $\left(\mathrm{g} \mathrm{kg}^{-1}\right)$ & 472,51 \\
Areia grossa $\left(\mathrm{g} \mathrm{kg}^{-1}\right)$ & 170,62 \\
Areia fina $\left(\mathrm{g} \mathrm{kg}^{-1}\right)$ & 301,89 \\
Silte $\left(\mathrm{g} \mathrm{kg}^{-1}\right)$ & 360,92 \\
Argila $\left(\mathrm{g} \mathrm{kg}^{-1}\right)$ & 166,57 \\
Densidade do solo $\left(\mathrm{kg} \mathrm{dm}^{-3}\right)$ & 1,42 \\
Densidade de particulas $\left(\mathrm{kg} \mathrm{dm}^{-3}\right)$ & 2,55 \\
Porosidade calculada $\left(\mathrm{dm}^{3} \mathrm{dm}^{-3}\right)$ & 0,44 \\
CEes $\left.(\mathrm{dS} \mathrm{m})^{-1}\right)$ & 0,66 \\
Sódio solúvel $\left(\mathrm{mmol}_{\mathrm{c}} \mathrm{L}^{-1}\right)$ & 3,48 \\
Cloro solúvel $\left(\mathrm{mmol}_{\mathrm{C}} \mathrm{L}^{-1}\right)$ & 15,00 \\
Potencial osmótico (MPa) & 0,013 \\
\hline
\end{tabular}

* Métodos utilizados: Análise granulométrica (método do densímetro); Densidade do solo (método da proveta); densidade de partículas (balão volumétrico); Porosidade: [1-(Ds/Dp)]; CEes: Condutividade elétrica do extrato de saturação (Richards, 1954)

Para a realização do experimento foram utilizadas amostras passadas em peneira com malha de $4 \mathrm{~mm}$ com o objetivo de preservar a microagregação do solo. As amostras foram acomodadas em colunas de PVC, confeccionadas com tubo de 
diâmetro interno de 100 e $200 \mathrm{~mm}$ de altura. O preenchimento do solo nas colunas foi realizado de forma a proporcionar uniformidade e homogeneidade mantendo-se a densidade do solo a $1,42 \mathrm{~kg} \mathrm{dm}^{-3}$, padronizando a relação massa:altura do solo na coluna.

Utilizaram-se soluções de $\mathrm{NaCl}$ nas concentrações de 0,20 , $30,40,50,60,70,80,90,100,110$ e $120 \mathrm{mmol}_{\mathrm{c}} \mathrm{L}^{-1}$, saturando o solo nas colunas por capilaridade. Após a saturação as colunas foram fechadas nas extremidades evitando perdas por drenagem (parte inferior) e por evaporação (parte superior). Manteve-se o ensaio nessas condições por $24 \mathrm{~h}$, tempo suficiente para equilibrar a relação de solução com as amostras de solo. Após o equilíbrio abriram-se as extremidades das colunas e o excesso de água foi drenado por ação gravitacional, durante $24 \mathrm{~h}$; em seguida, foram instaladas as cápsulas porosas (extratores), previamente saturadas em água desaerada inserindo-as nas colunas a $13 \mathrm{~cm}$ de profundidade, com o auxílio de um trado de rosca com diâmetro semelhante ao dos extratores.

A extração da solução do solo nas colunas foi feita via bomba de vácuo aplicando-se tensão de $75 \mathrm{kPa}$. Decorridas $24 \mathrm{~h}$, coletou-se a solução presente no extrator com auxílio de seringa e mangueira; em seguida, os extratores foram removidos e coletadas amostras de solo ao redor das cápsulas para determinação da umidade gravimétrica e posterior correção das variáveis obtidas pela cápsula porosa.

Após ensaios de "extração via cápsulas porosas", o solo contido em cada coluna foi secado ao ar, destorroado e passado em peneira com malha de $2 \mathrm{~mm}$ (TFSA). Após este procedimento parte dessa TFSA foi utilizada para preparo das pastas de saturação; o restante da TFSA foi reservado para ser usado nos ensaios visando à obtenção do extrato via relação solo: água.

Foram pesados $400 \mathrm{~g}$ da TFSA em recipientes apropriados adicionando-se água destilada até que atingisse o ponto de pasta de saturação representado pelo aspecto espelhado e deslizamento da pasta na espátula, como descrito por Richards (1954); em seguida, vedaram-se os recipientes para evitar perdas de água da pasta por evaporação, mantendo as pastas nessas condições, por $12 \mathrm{~h}$; continuando, as pastas foram colocadas em sistema de vácuo (funil de Büchner-kitassato-bomba) para obtenção dos extratos de pasta de saturação acondicionado-os em tubos hermeticamente fechados e mantidos sob refrigeração para análises posteriores.

Com os dados da relação água de saturação e massa de solo seco em estufa determinou-se a umidade gravimétrica do solo na pasta de saturação (Ups) obtendo-se a umidade de saturação $(\mathrm{S} \%)$.

O restante da TFSA não utilizada na pasta de saturação foi usado no terceiro ensaio preparando-se as proporções solo:água (massa:volume): 1:2; 1:5 e 1:10; para isto, pesaram-se $20 \mathrm{~g}$ de TFSA em tubos apropriados nos quais foram adicionadas quantidades de água destilada para manter as diferentes proporções. Os conjuntos tubo-solo-água foram agitados em agitador Tipo Wagner, a $50 \mathrm{rpm}$, durante $10 \mathrm{~min}$; após este procedimento as amostras ficaram em repouso durante $1 \mathrm{~h} \mathrm{e}$ só então se realizou uma nova agitação, pelo mesmo período de tempo. Após a agitação foi testado, ainda, o processo de filtragem das amostras utilizando-se funis de vidro com papel de filtro qualitativo. Assim, têm-se mais dois grupos de extratos: extrato solo:água sem filtração e com filtração. A escolha desses procedimentos teve como objetivo observar a influência do processo de filtragem nos resultados da CE uma vez que o mesmo demanda mais custos e tempo.

Para todas as soluções extraídas dos métodos citados anteriormente foram realizadas medidas de condutividade elétrica (CE), potencial osmótico (PO), sódio e cloreto solúveis. A CE foi determinada com o auxílio de condutivímetro digital. Para medida do PO uma alíquota de $10 \mu \mathrm{L}$ da solução do solo foi utilizada para determinação da osmolalidade usando-se um osmômetro de pressão de vapor, modelo Wescor 5520. Os valores de PO foram obtidos a partir da osmolalidade (mmol $\mathrm{kg}^{-1}$ ) mediante o uso da equação de Van't Hoff (Souza et al., 2012). O sódio solúvel foi dosado em fotômetro de chama e o cloreto determinado por titulação com nitrato de prata.

Como os valores de CE, PO, sódio e cloreto determinados nas soluções obtidas das cápsulas porosas apresentavam umidade diferente da saturação no momento da coleta, foi necessário realizar correção em função da umidade do solo obtida na pasta de saturação. Os valores corrigidos foram denominados "estimados" (Lao, 2003) obtidos por meio da Eq. 1.

$$
\mathrm{CE}, \mathrm{PO}, \mathrm{Na}^{+}, \mathrm{Cl}^{-} \text {estimados }=\frac{\left[\left(\mathrm{CE}, \mathrm{PO}, \mathrm{Na}^{+}, \mathrm{Cl}^{-}\right) \mathrm{cp}\right] \cdot \mathrm{Ucp}}{\mathrm{Ups}}
$$

em que:

$\mathrm{CE}, \mathrm{PO}, \mathrm{Na}^{+}, \mathrm{Cl}^{-}$estimados - condutividade elétrica (CE), potencial osmótico (PO) do extrato de saturação, sódio e cloreto, estimados a partir dos valores medidos na solução do solo obtida com extrator de cápsula porosa, $\mathrm{CE}\left(\mathrm{dS} \mathrm{m}^{-1}\right)$; $\mathrm{PO}$ (MPa); $\mathrm{Na}$ e $\mathrm{Cl}\left(\mathrm{mmol}_{\mathrm{c}} \mathrm{L}^{-1}\right)$

$\mathrm{CE}, \mathrm{PO}, \mathrm{Na}^{+}, \mathrm{Cl}^{-} \mathrm{cp}$ - condutividade elétrica, potencial osmótico, sódio e cloreto obtidos com extrator de cápsula porosa, $\mathrm{CE}\left(\mathrm{dS} \mathrm{m} \mathrm{m}^{-1}\right)$

PO ( MPa); Ucp - umidade do solo no momento da retirada da solução do extrator de cápsula porosa $\left(\mathrm{g} \mathrm{g}^{-1}\right)$

Ups - umidade do solo na pasta saturada, $\left(\mathrm{g} \mathrm{g}^{-1}\right)(\mathrm{S} \%$ umidade de saturação)

\section{Resultados e Discussão}

Observaram-se equações de regressões lineares significativamente positivas $(\mathrm{P}<0,01)$ entre a $\mathrm{CE}$ do extrato de saturação $\left(\mathrm{CE}_{\mathrm{es}}\right)$ e a $\mathrm{CE}$ obtida na solução extraída pelas cápsulas porosas (Figura 1A). É interessante observar que, ao corrigir os valores de CE medidos nas cápsulas porosas por meio da umidade atual no momento de extração e com a umidade da pasta de saturação (Eq. 1) consegue-se uma equação que evidencia a recomendação do uso de extratores de cápsulas porosas em substituição à pasta de saturação (Figura 1B). Isto é possível de ser visualizado pelo perfeito ajuste à reta 1:1. Quando não é feita a correção da umidade os valores de CE são superestimados uma vez que a umidade no momento da extração as solução via cápsula, comumente em condição de solo não saturado, é menor do que a umidade via extração da pasta de saturação (Figura 1A). 

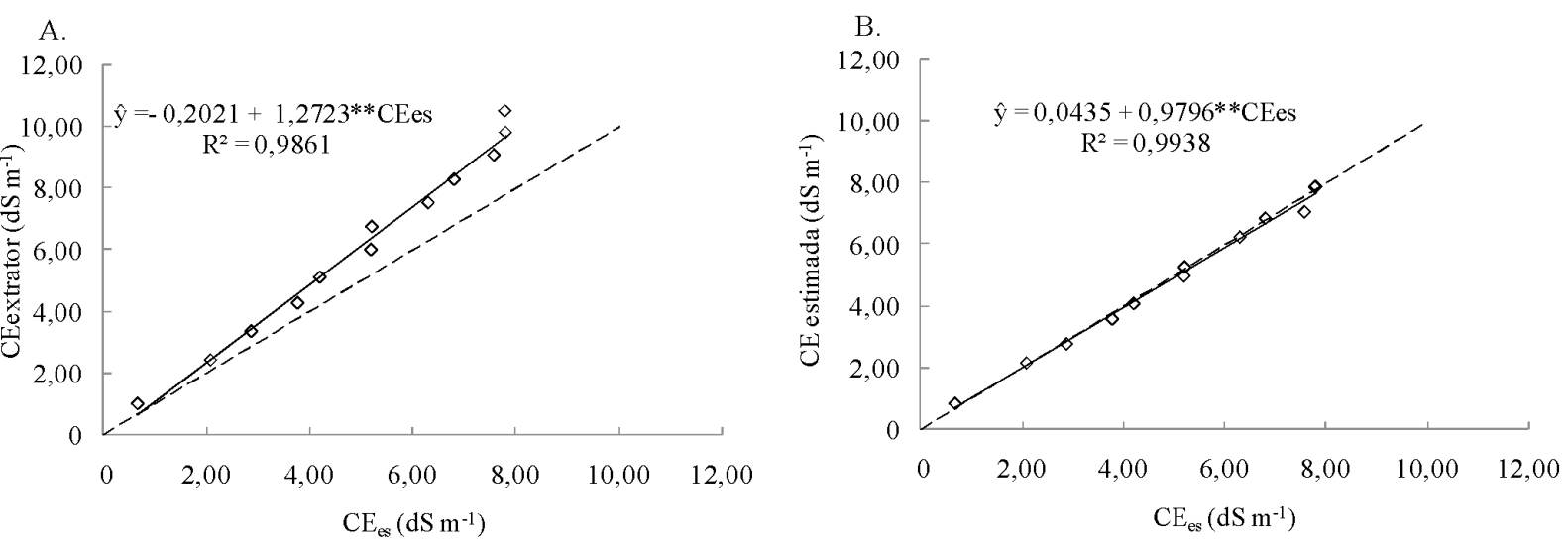

A linha pontilhada representa a reta 1:1

Figura 1. Relações entre $(A) C E_{e s}\left(d S m^{-1}\right)$ e as $C E$ obtidas na solução extraída pela cápsula porosa e $(B) C E_{e s}$ e a $C E$ estimada

A condutividade elétrica da solução do solo, embora seja uma medida simples e rápida, ainda é a principal variável utilizada para avaliação dos riscos de sais no sistema soloplanta. Relações que expressem o valor da $\mathrm{CE}$ encontrado no extrato da pasta de saturação (método tido como referência e adotado em várias regiões do mundo) com valores de $\mathrm{CE}$ obtidos em extrações por meio de cápsulas extratoras porosas, possibilitam um manejo mais eficiente uma vez que possibilita a tomada de decisão ainda em condição de campo, como necessidade de uso de fração de lixiviação e quantidade de adubos a ser aplicada ao solo. Segundo Marques et al. (2012) a extração da solução do solo via extratores é mais rápida e pode ser obtida pontualmente ao longo do tempo e no mesmo espaço amostral, sem a necessidade de coleta de amostra de solo.

Ao comparar os valores de potencial osmótico (MPa) do extrato da pasta de saturação com os da solução extraída pelas cápsulas extratoras (Figuras $2 \mathrm{~A}$ e $2 \mathrm{~B}$ ) o comportamento de ajuste dos dados foi semelhante àquele obtido para a $\mathrm{CE}$, isto é, novamente a correção dos valores do PO das soluções extraídas pelas cápsulas extratoras, quando corrigidos com as umidades do momento da coleta e da pasta de saturação, favorece o ajuste dos dados à reta 1:1 (Figura 2B).

A medida do potencial osmótico, ao contrário da condutividade elétrica, pouco vem sendo adotada em trabalhos

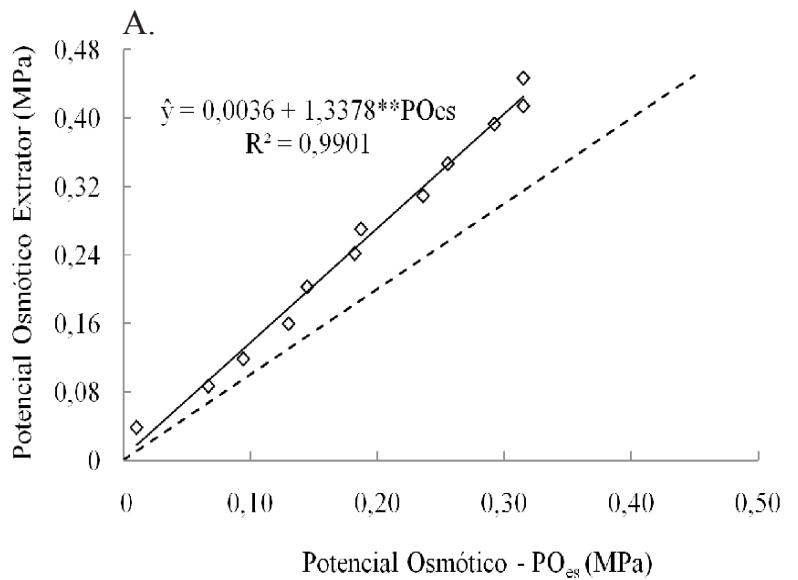

que envolvem a temática de salinidade. Entretanto, Ben-Gal et al. (2009) apontam esta medida como apropriada e indicada para avaliar o risco dos sais para o sistema solo-planta. Neste sentido, recomenda-se incluir referida essa variável nos estudos que tratem do tema (Souza et al., 2012).

A determinação do potencial osmótico requer o uso do osmômetro para determinação da quantidade total de solutos, moles $\mathrm{L}^{-1}$ e consequente aplicação na fórmula de Van't Hoff (Souza et al., 2012). Entretanto, o osmômetro não é um equipamento comum na maioria dos laboratórios de análise de água e solo no Brasil ao contrário da condutividade elétrica que requer um equipamento mais simples, como o condutivímetro. Neste sentido observa-se que é possível obter, com segurança, os valores de potencial osmótico do extrato de saturação a partir de medidas de condutividade elétrica do extrato de saturação, para amostras de Neossolo Flúvico investigado (Figura 3). A equação obtida pode ser utilizada para estimar o valor do potencial osmótico com precisão para a classe de Neossolo Flúvico com características semelhantes às da corrente pesquisa.

As concentrações de cloreto após a instalação das cápsulas extratoras apresentam equações lineares significativamente positivas $(\mathrm{P}<0,01)$ quando comparadas com as concentrações aplicadas (Figura 4), efeito evidenciado quando se observa a linha 1:1; este comportamento foi devido, sem dúvida, à condição

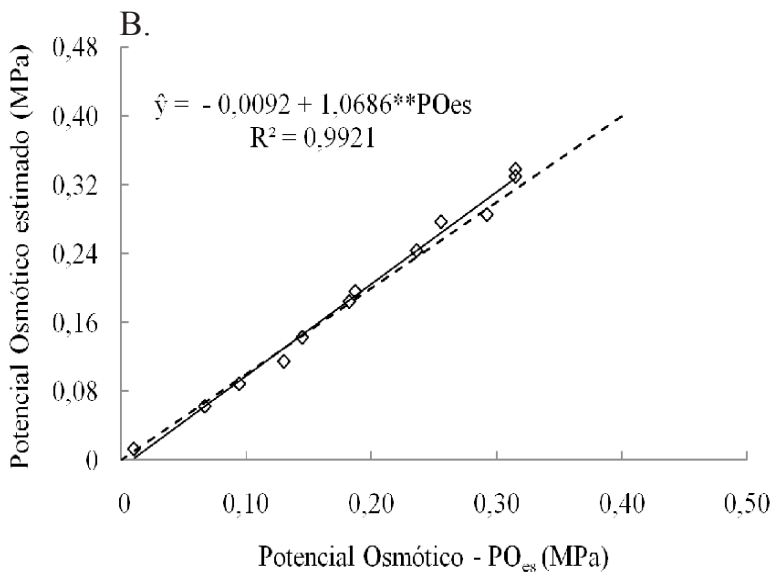

A linha pontilhada representa a reta 1:1

Figura 2. Relações entre o (A) POes (MPa) e os valores de PO obtidos na solução extraída pela cápsula porosa e o (B) POes (MPa) e o PO estimado a partir dos valores encontrados na cápsula extratora 


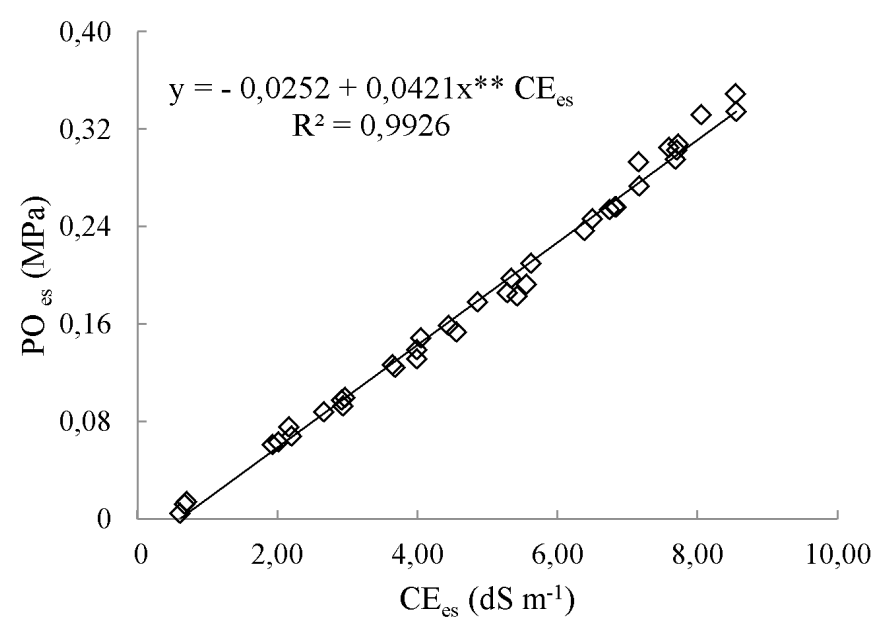

Figura 3. Relação entre a condutividade elétrica do extrato de saturação e o potencial osmótico do extrato de saturação

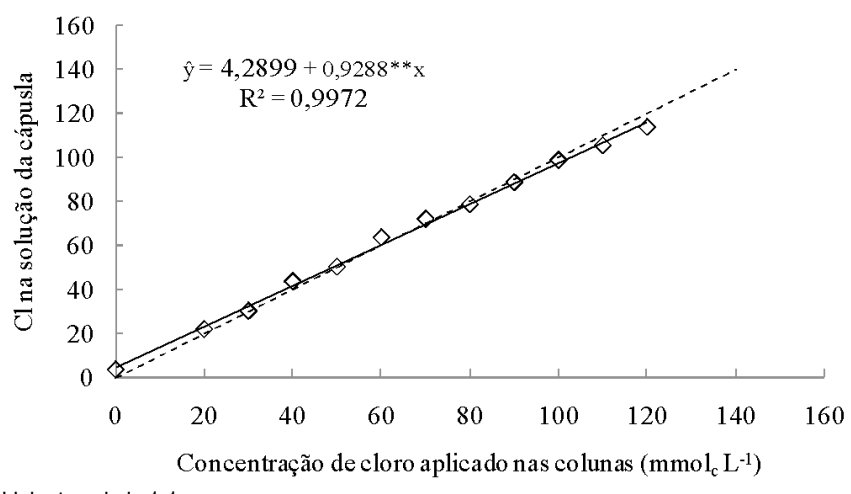

Linha tracejada 1:1

Figura 4. Equação de regressão entre a concentração de cloreto aplicado nas colunas e o determinado nas soluções extraídas da cápsula porosa

de disponibilidade deste elemento na solução do solo. A alta percentagem de areia + silte (Tabela 1) justifica a predominância do ânion em solução, pela ausência de cargas elétricas na superfície dos minerais que constituem essas frações. Salientase, também que, possivelmente, os argilominerais presentes na fração argila do solo sejam do tipo 2:1, que apresentam balanço de cargas predominantemente negativas. Comportamento similar foi encontrado para o ânion nitrato em dois solos de texturas franco arenosa e franco argilosa (Lima, 2009).

Quando se comparou o cloreto determinado no extrato de saturação com o estimado pela solução extraída com a cápsula porosa (Figura 5) obteve-se, como melhor ajuste, o da equação linear $(\mathrm{P}<0,01)$ com elevado coeficiente de determinação $\left(\mathrm{R}^{2}=\right.$ $0,9864)$ que indica a viabilidade de determinação deste elemento na solução do solo, extraída via cápsula porosa.

As concentrações de sódio determinadas na solução extraída pela cápsula porosa quando comparada com as soluções de sódio aplicadas (Figura 6A) evidenciam que pode ter ocorrido adsorção de sódio e também uma concentração deste elemento em virtude de uma umidade menor do solo. Salienta-se que a solução de $\mathrm{NaCl}$ foi aplicada de modo a saturar o solo e a instalação do extrator só ocorreu após a drenagem da água gravitacional, ou seja, quando o solo se encontrava na

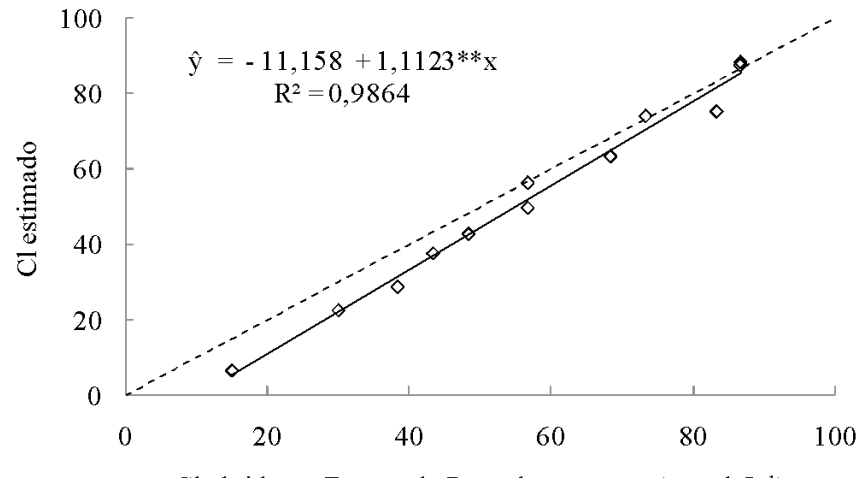

Cl obtido no Extrato da Pasta de saturação $\left(\operatorname{mmol}_{\mathrm{c}} \mathrm{L}^{-1}\right)$

Figura 5. Equação de regressão entre o valor de cloreto obtido no extrato de saturação e o cloreto estimado

A.

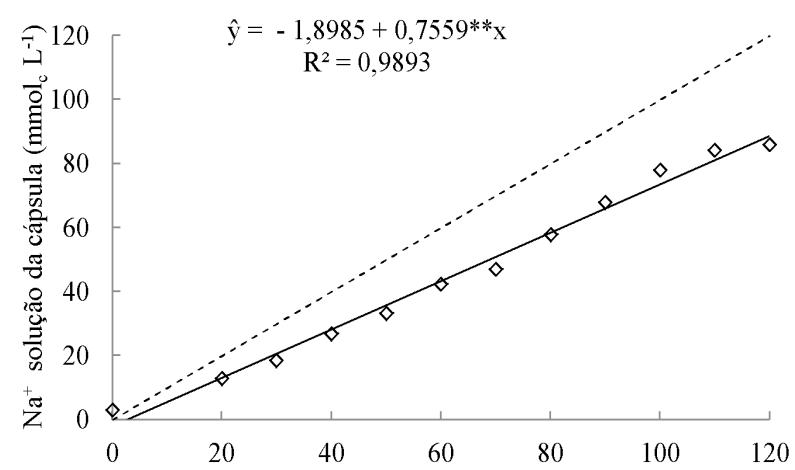

B.

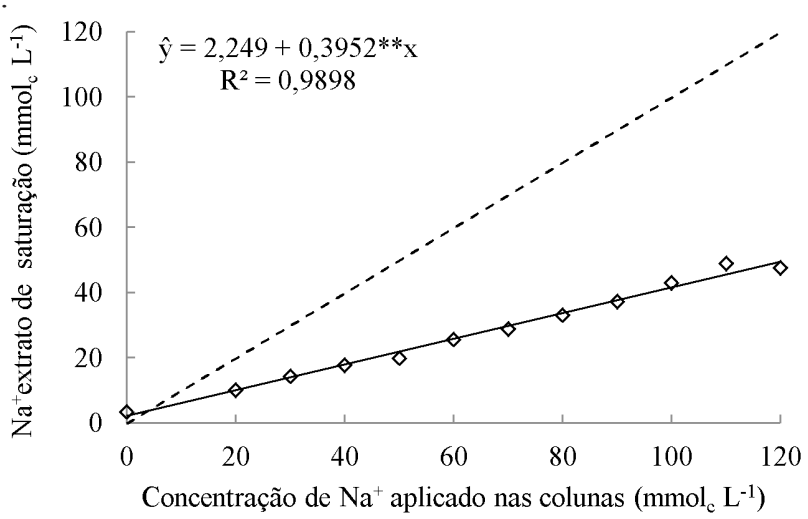

C.

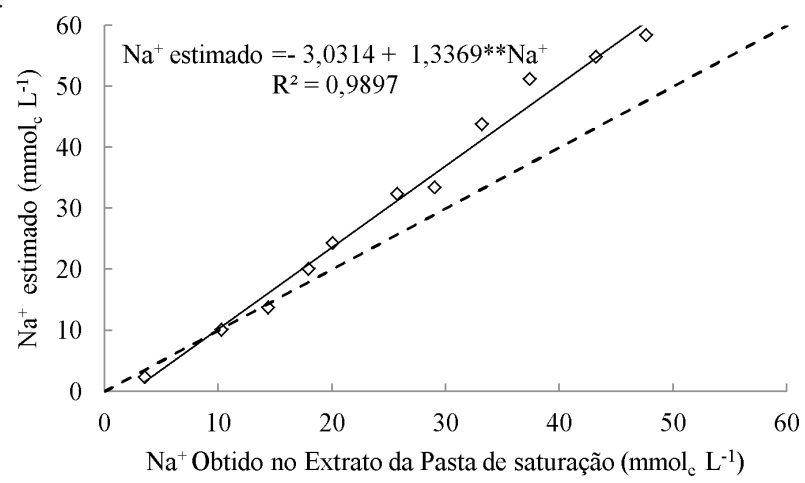

Figura 6. Equações de regressão (A) entre a concentração de sódio aplicado nas colunas e o determinado na solução extraída da cápsula porosa (B) entre a concentração de sódio aplicado nas colunas e o determinado no extrato da pasta de saturação $(\mathrm{C})$ entre o sódio obtido no extrato de saturação e o sódio estimado 
capacidade campo. Esta redução foi bem maior quando se determinou o sódio através do extrato da pasta de saturação (Figura 6B). Gloaguen et al. (2009a,b) apresentam uma discussão interessante quanto à concentração de íons em função do diâmetro de poros e, consequentemente, da umidade do solo.

Ao se comparar o sódio extraído pela pasta de saturação e o estimado a partir das concentrações na solução obtida com extratores de cápsula porosa em função da umidade, observase uma relação linear significativa (Figura 6C) indicando a viabilidade da determinação do sódio na solução extraída via cápsula porosa.

Dias et al. (2005) e Oliveira et al. (2011) afirmam que é possível, com auxílio dos extratores de solução por cápsulas porosas, monitorar a concentração total de sais na solução do solo e manter a salinidade em nível desejado controlando a condutividade elétrica da solução extraída. No entanto, é interessante e recomendável que sejam avaliadas metodologias de extração da solução do solo para as diversas classes de solos encontradas no Brasil e que constem no Sistema Brasileiro de Classificação de Solo bem como considerem manejos diferenciados em determinadas condições (Gloaguen et al., 2009b; Oliveira et al., 2011)

Os valores de condutividade elétrica do extrato de saturação e da cápsula porosa foram superiores aos encontrados nas suspensões filtradas (Tabela 2 e Figura 7) e não filtradas (Figura 8) dos extratos em diferentes relações solo:água (1:2, 1:5 e $1: 10)$ em função principalmente da diluição das amostras. Essas variações podem ocorrer em função da capacidade de troca de cátions, da composição e concentração de sais, da dissolução mineral e das características relativas à retenção de água no solo, que alteram os valores encontrados nos extratos diluídos obtidos de relação solo:água.

Tabela 2. Valores médios de condutividade elétrica de soluções extraídas por diferentes métodos em amostras de Neossolo Flúvico após aplicação de soluções de $\mathrm{NaCl}$

\begin{tabular}{|c|c|c|c|c|c|}
\hline \multirow{3}{*}{$\begin{array}{c}\mathrm{NaCl} \\
\left(\mathrm{mmol}_{\mathrm{c}} \mathrm{L}^{-1}\right)\end{array}$} & \multicolumn{2}{|c|}{ Extrato } & \multicolumn{3}{|c|}{ Relação solo-água } \\
\hline & PS & $\mathbf{C P}$ & $(1: 2)$ & $(1: 5)$ & $(1: 10)$ \\
\hline & \multicolumn{5}{|c|}{ Condutividade elétrica $\left(\mathrm{dS} \mathrm{m}^{-1}\right)$} \\
\hline 0 & $0,66 \pm 0,05$ & $0,82 \pm 0,04$ & $0,20 \pm 0,01$ & $0,13 \pm 0,02$ & $0,07 \pm 0,01$ \\
\hline 20 & $2,07 \pm 0,13$ & $2,15 \pm 0,05$ & $0,43 \pm 0,03$ & $0,20 \pm 0,02$ & $0,11 \pm 0,01$ \\
\hline 30 & $2,87 \pm 0,14$ & $2,76 \pm 0,09$ & $0,57 \pm 0,01$ & $0,26 \pm 0,03$ & $0,13 \pm 0,01$ \\
\hline 40 & $3,77 \pm 0,19$ & $3,57 \pm 0,10$ & $0,70 \pm 0,01$ & $0,29 \pm 0,02$ & $0,15 \pm 0,01$ \\
\hline 50 & $4,19 \pm 0,31$ & $4,08 \pm 0,09$ & $0,83 \pm 0,03$ & $0,34 \pm 0,01$ & $0,17 \pm 0,01$ \\
\hline 60 & $5,19 \pm 0,29$ & $4,97 \pm 0,38$ & $0,92 \pm 0,04$ & $0,40 \pm 0,02$ & $0,21 \pm 0,02$ \\
\hline 70 & $5,20 \pm 0,66$ & $5,26 \pm 0,35$ & $1,01 \pm 0,02$ & $0,43 \pm 0,01$ & $0,23 \pm 0,01$ \\
\hline 80 & $6,29 \pm 0,91$ & $6,24 \pm 0,37$ & $1,12 \pm 0,06$ & $0,52 \pm 0,03$ & $0,26 \pm 0,02$ \\
\hline 90 & $6,80 \pm 0,05$ & $6,85 \pm 0,57$ & $1,22 \pm 0,03$ & $0,58 \pm 0,03$ & $0,30 \pm 0,02$ \\
\hline 100 & $7,57 \pm 1,03$ & $7,06 \pm 0,49$ & $1,31 \pm 0,06$ & $0,60 \pm 0,03$ & $0,32 \pm 0,02$ \\
\hline 110 & $7,80 \pm 0,70$ & $7,88 \pm 0,42$ & $1,51 \pm 0,05$ & $0,67 \pm 0,01$ & $0,35 \pm 0,01$ \\
\hline 120 & $7,78 \pm 0,23$ & $7,86 \pm 0,27$ & $1,55 \pm 0,08$ & $0,70 \pm 0,03$ & $0,37 \pm 0,01$ \\
\hline
\end{tabular}

Para avaliar a influência do papel do processo de filtragem nos resultados de condutividade elétrica das suspensões, procedeu-se à comparação dos valores de $\mathrm{CE}$ obtidos a partir dos dois processos (com e sem filtragem). Observa-se que os pontos medidos se apresentam próximos da linha tracejada 1:1, indicando alta correlação entre esses métodos; entretanto, a

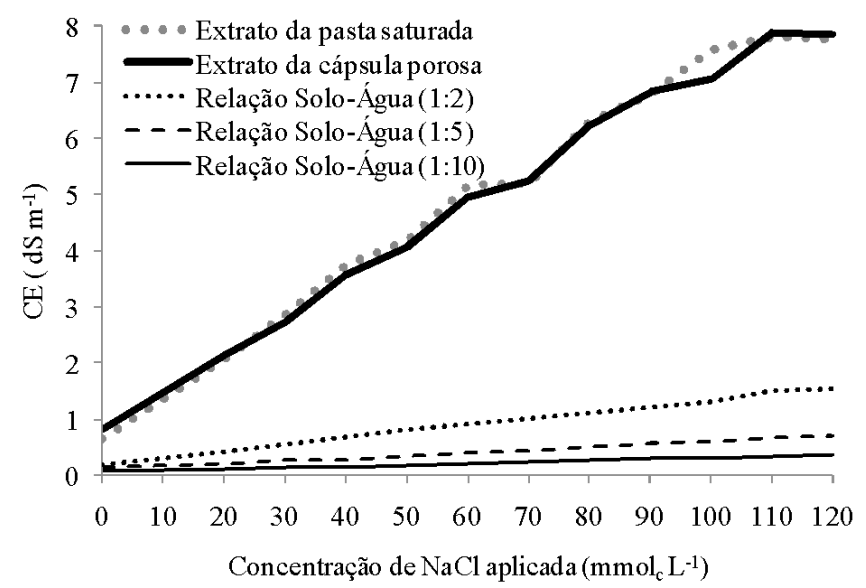

Figura 7. Valores de CE (dS m-1) de amostras de solução do solo obtidas pela pasta de saturação, cápsulas porosas e relações filtradas solo:água 1:2, 1:5 1 1:10 em função da concentração de $\mathrm{NaCl}$ aplicada nas colunas

A.

B
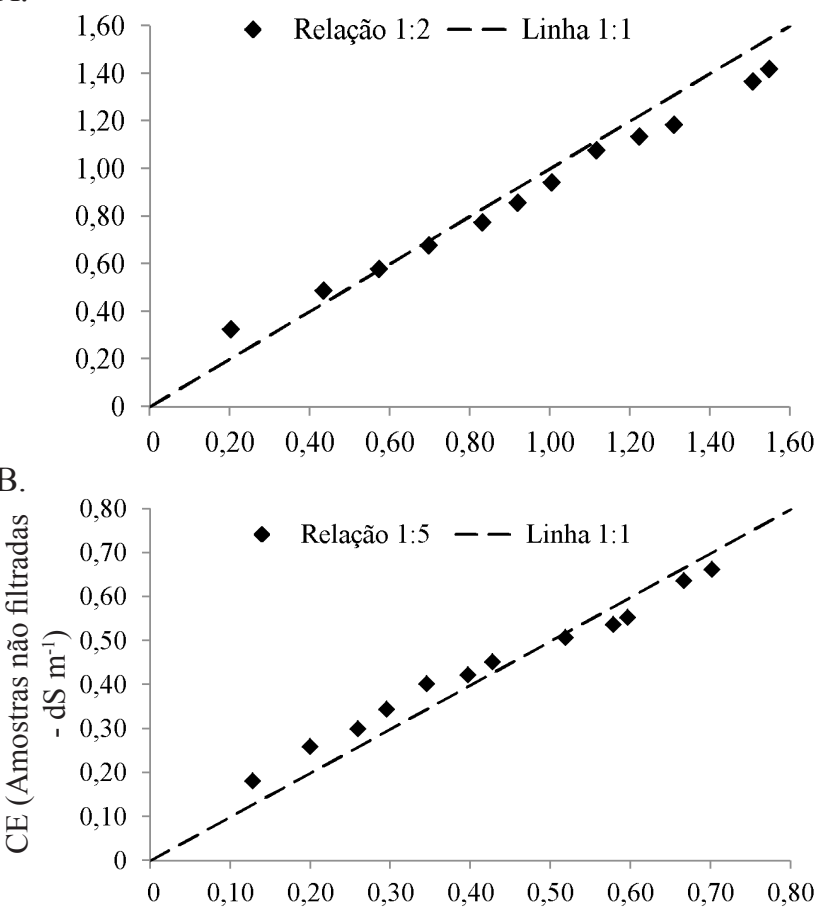

C.

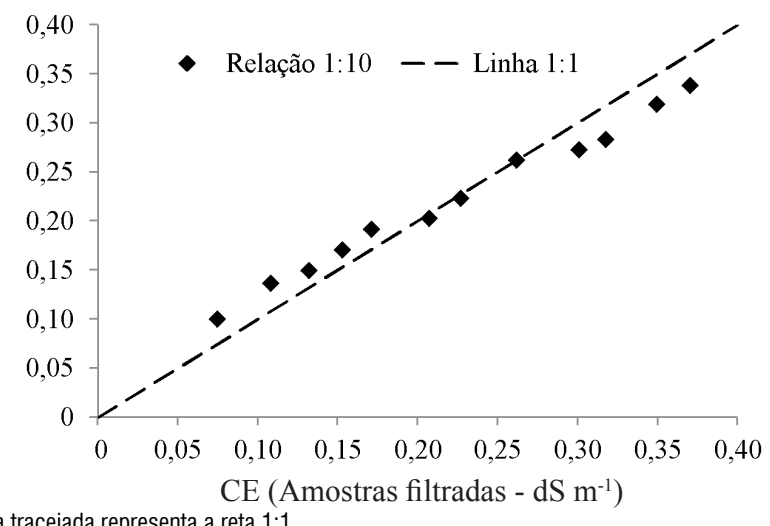

A linha tracejada representa a reta 1:1

Figura 8. Relações entre a $\mathrm{CE}\left(\mathrm{dS} \mathrm{m}^{-1}\right)$ das amostras filtradas e não filtradas nas relações solo:água (A) 1:2,

(B) $1: 5$ e (C) $1: 10$ 
determinação de íons solúveis é dificultada em amostras que não sofrem o processo de filtragem; recomenda-se, então, quando o intuito é determinar tais elementos, o uso da filtragem.

Já para validação dos processos no pretratamento das amostras (filtradas e não filtradas) para obtenção dos valores de CE, observa-se que a filtração não interfere nos resultados (Figura 9)

Com base nas relações estabelecidas entre a $\mathrm{CE}_{\mathrm{es}}$ e os valores de condutividade elétrica das três relações solo:água avaliadas $\left(\mathrm{CE}_{1: 2}, \mathrm{CE}_{1: 5}, \mathrm{CE}_{1: 10}\right)$ com e sem processo de filtragem (Figura 9) nota-se a alta relação existente entre as variáveis relacionadas em que todas apresentaram valores de coeficiente de determinação acima de 0,96 ; portanto, podese afirmar que é possível estimar $\mathrm{CE}_{\mathrm{es}}$ através do preparo de extratos aquosos, uma maneira bem mais rápida e fácil,
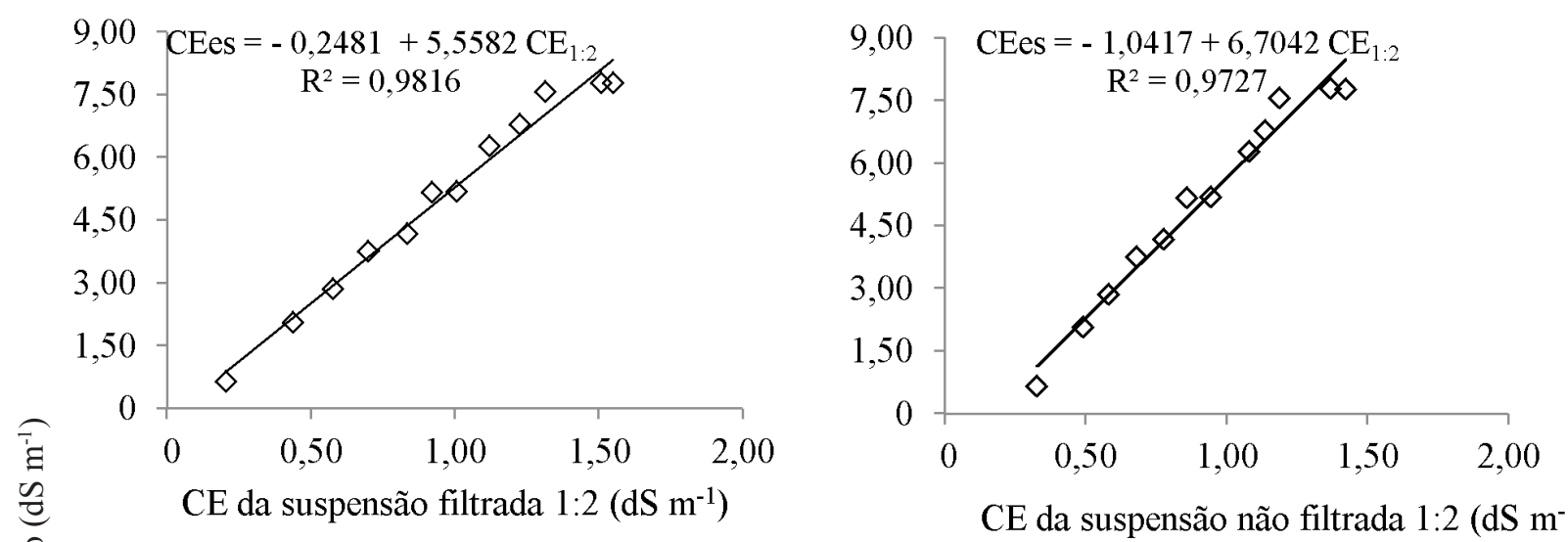

$\mathrm{CE}$ da suspensão não filtrada $1: 2\left(\mathrm{dS} \mathrm{m} \mathrm{m}^{-1}\right)$

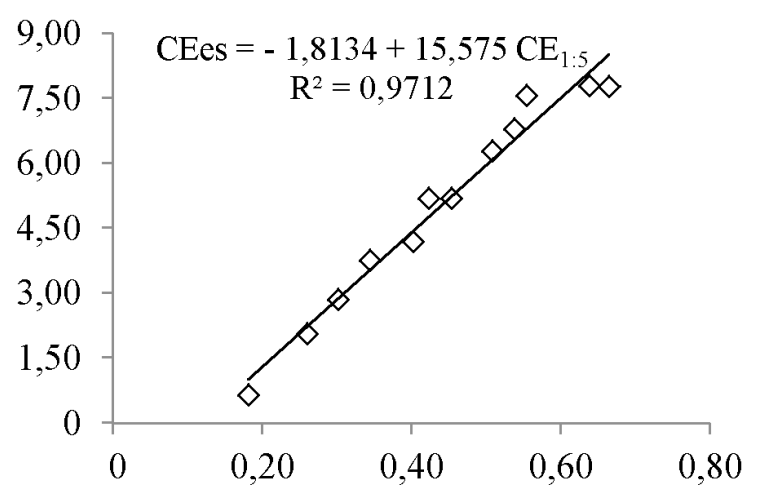

CE da suspensão não filtrada $1: 5\left(\mathrm{dS} \mathrm{m}^{-1}\right)$

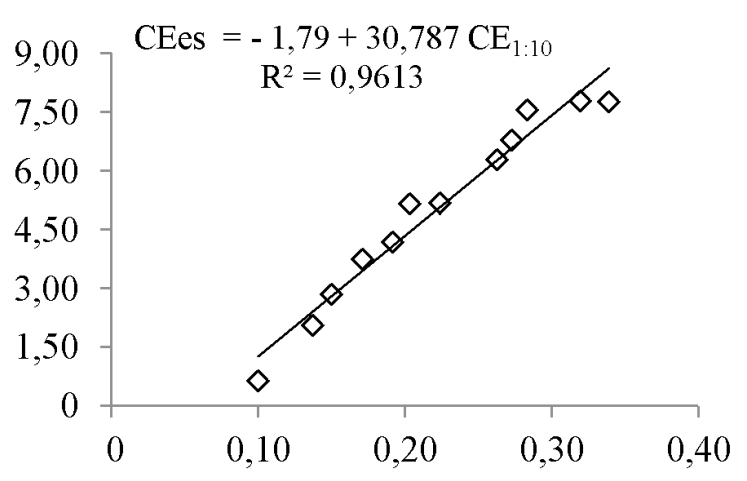

CE da suspensão não filtrada $1: 10\left(\mathrm{dS} \mathrm{m}^{-1}\right)$

Figura 9. Equações de regressão lineares relacionando os valores de condutividade elétrica $\left(\mathrm{dS} \mathrm{m}^{-1}\right)$ das três suspensões solo:água $\left(\mathrm{CE}_{1: 2^{\prime}} \mathrm{CE}_{1: 5,}, \mathrm{CE}_{1: 10}\right)$ filtradas e não filtradas e a $\mathrm{CE}$ do extrato da pasta de saturação do solo 
Trabalhos desse tipo são bem aceitos em razão da necessidade do conhecimento das relações iônicas na solução de diversas classes de solos incluindo-se as variações dos atributos físicos e químicos dentro de cada uma delas. Assim, métodos rápidos, práticos e eficientes de extração da solução do solo contribuem para implementação de práticas de monitoramento e manejo adequados em solos que apresentam históricos de contaminação ambiental, especialmente a salinização; além disto, serve como parâmetro preventivo para a ocorrência desse processo em áreas em que se pratica a irrigação e o uso de grandes quantidades de adubo.

\section{Conclusões}

1. Os extratores munidos de cápsulas porosas apresentamse como alternativa viável para extração da solução do solo e monitoramento da condutividade elétrica, potencial osmótico e composição iônica.

2. Os valores de condutividade elétrica e sódio solúvel determinados através dos extratos aquosos em diferentes proporções $(1: 2,1: 5,1: 10)$ apresentaram ajustes lineares com elevados coeficientes de determinação quando confrontados com aqueles determinados pelo método padrão (mais usual) da pasta de saturação.

3. Quando o intuito é somente a determinação da condutividade elétrica, o processo de filtragem pode ser dispensado, economizando tempo e recursos financeiros.

\section{Literatura Citada}

Adams, F.; Burmester, C.; Hue, N. V.; Long, F. L. A comparison of column-displacement and centrifuge methods for obtaining soil solutions. Soil Science Society of American Journal, v.44, p.733-735, 1980.

Ben-Gal, A.; Borochov-Neori, H.; Yermiyahu, U.; Shani, U. Is osmotic potential a more appropriate property than electrical conductivity for evaluating whole-plant response to salinity? Environmental and Experimental Botany, v.65, p.232-237, 2009.

Blanco, F. F.; Folegatti, M. V.; Henrique Neto, D. Doses de N e K no tomateiro sob estresse salino: I. Concentração de nutrientes no solo e na planta. Revista Brasileira de Engenharia Agrícola e Ambiental, v.12, p.26-33, 2008.

Chowdhury, N.; Marschner, P.; Burns, R. G. Soil microbial activity and community composition: Impact of changes in matric and osmotic potential. Soil Biology \& Biochemistry,v.43, p.1229-1236, 2011a.

Chowdhury, N.; Marschner, P.; Burns, R. G. Response of microbial activity and community structure to decreasing soil osmotic and matric potential. Plant and Soil v.344, p.241-254, 2011b.

Dias, N. da S.; Duarte, S. N.; Gheyi, H. R.; Medeiros, J. F. de; Soares, T. M. Manejo da fertirrigação e controle da salinidade do solo sob ambiente protegido, utilizandose extratores de solução do solo. Revista Brasileira de Engenharia Agrícola e Ambiental, v.9, p.496-504, 2005.

Dias, N. da S.; Duarte, S. N.; Medeiros, J. F. de; Telles Filho, J. F. Salinidade e manejo da fertirrigação em ambiente protegido. I: Efeitos sobre o crescimento do meloeiro. Irriga, v.11, p.208-218, 2006.
Elkhatib, E. A.; Bennett, O. L.; Baligar, V. C.; Wright, R. J. A centrifuge method for obtaining soil solution using an immiscible liquid. Soil Science Society of American Journal, v.50, p.297-299, 1986.

Gloaguen, T. V.; Pereira, F. A. C.; Gonçalves, R. A. B.; Paz, V. S. Sistema de extração sequencial da solução na macro e microporosidade do solo. Revista Brasileira de Engenharia Agrícola e Ambiental, v.13, p.544-550, 2009a.

Gloaguen, T. V.; Pereira, F. A. C.; Gonçalves, R. A. B.; Paz, V. S. Composição química da solução do solo nas diferentes classes de poro do solo. Revista Brasileira de Ciência do Solo, v.33, p.1105-1113, 2009b.

Lao, M. T.; Jiménez, S.; Eymar, E.; Fernández, E. J. Nutrient levels of the solution obtained by means of suction cups in intensive tomato cultivation. Phyton,v.4, p.29-37, 2004.

Lao, M. T.; Jiménez, S.; Eymar, E.; Fernández, E. J.; Jiménez, R. Determination of spatial variability of nutrient composition of soil solutions in greenhouses by using suction cups. Communications in Soil Science and Plant Analysis, v.34, p.865-879, 2003.

Lima, C. J. G. de S. Calibração e manejo de extratores de cápsulas porosas e transdutores de pressão para monitoramento de íons na fertirrigação. Piracicaba: ESALQ, 2009. 109p. Dissertação Mestrado

Marques, J. D. de O.; Luizão, F. J.; Teixeira, W. G.; Ferreira, S. J. Variações do carbono orgânico dissolvido e de atributos físicos do solo sob diferentes sistemas de uso da terra na Amazônia Central. Revista Brasileira de Ciência do Solo, v.36, p.611-622, 2012.

Miranda, J.; Costa, L. M. da.; Ruiz, H. A,; Einloft, R. Composição química da solução de solo sob diferentes coberturas vegetais e análise de carbono orgânico solúvel no deflúvio de pequenos cursos de água. Revista Brasileira de Ciência do Solo, v.30, p.633-647, 2006.

Oliveira, F. de A.; Medeiros, J. F. de; Duarte, S. N.; Silva Júnior, M. J. da.; Campelo, C. M. Calibração de extratores providos de cápsula porosa para monitoramento da salinidade e da concentração de íons. Engenharia Agrícola, v.31, p.520-528, 2011

Pereira, F. A. M.; Fernandez, M. B.; Etchevers, J. D.; Gheyi, H. R. Efeito da relação solo-água na condutividade elétrica. Agropecuária Técnica, v.2, p.148-154, 1981.

Richards, L.A. Diagnosis and improvement of saline and alkali soils. Washington: United States Salinity Laboratory, 1954. 160p. USDA, Agriculture Handbook 60

Schlotter, D.; Schack-Kirchner, H.; Hildebrand, E. E.; Wilpert, $\mathrm{K}$. von. Equivalence or complementarity of soil-solution extraction methods. Journal of Plant Nutrition and Soil Science, v.175, p.236-244, 2012.

Silva Júnior, M. J.; Duarte, S. N.; Oliveira, F. A.; Medeiros, J. F. de; Dutra, I. Resposta do meloeiro à fertigação controlada através de íons da solução do solo: Desenvolvimento vegetativo. Revista Brasileira de Engenharia Agrícola e Ambiental, v.14, p.715-722, 2010.

Souza, E. R. de; Freire, M. B. G. dos S.; Cunha, K. P. V.; Nascimento, C. W. A.; Ruiz, H. A., Lins, C. T. Biomass, anatomical changes and osmotic potential in Atriplex nummularia Lindl. cultivated in sodic saline soil under water stress. Environmental and Experimental Botany, v.82, p.20-27, 2012. 